\title{
KAJIAN PERUBAHAN MANUAL SUPERVISI JALAN DENGAN SPESIFIKASI UMUM 2018 BINA MARGA
}

\author{
Bertho Orbain Sowolino \\ Subdit Standar dan Pedoman \\ Direktorat Pembangunan Jalan \\ Ditjen Bina Marga, Kementerian PUPR \\ Jln. Pattimura No. 20, Jakarta Selatan \\ berthoorbains@gmail.com \\ Prayoga Luthfil Hadi \\ Magister Teknik Sipil \\ Universitas Katolik Parahyangan \\ Jln. Ciumbuleuit No. 94, Bandung 40141 \\ prayoga.lh@gmail.com
}

\author{
Zakaria Mujahid \\ Subdit Standar dan Pedoman \\ Direktorat Pembangunan Jalan \\ Ditjen Bina Marga, Kementerian PUPR \\ Jln. Pattimura No. 20, Jakarta Selatan \\ Zakaria.mujahid@yahoo.co.id \\ Wimpy Santosa \\ Fakultas Teknik \\ Universitas Katolik Parahyangan \\ Jln. Ciumbuleuit No. 94, Bandung 40141 \\ wimpy.santosa@gmail.com
}

\begin{abstract}
In order to support the acceleration of Indonesia's economic growth, massive infrastructure development must be carried out. The movement of goods and people must be able to run smoothly to accelerate economic growth. One type of infrastructure that can provide direct support is road infrastructure. Roads have an important role in regional development both from economic, social, cultural and environmental aspects. With its flexible nature, it can reach various regions and its development methods are relatively easy, the road being a favorite infrastructure to be developed. To achieve good quality road construction, a general specification must be met. In 2014, the Directorate General of Highways issued the 2010 General Specification (Revision 3) which was completed with the Road Supervision Manual document that referred to the specification. But with the increasing need for quality road construction and increasing awareness of the importance of maintenance activities, in 2018 the Directorate General of Highways issued a General Specification 2018. Therefore, it is necessary to understand the changes of the General Specifications and changes in the Road Supervision Manual.
\end{abstract}

Keywords: infrastructure development, road construction, general spesification, supervision manual

\begin{abstract}
Abstrak
Untuk mendukung percepatan pertumbuhan ekonomi Indonesia, pembangunan infrastruktur secara masif harus dilakukan. Pergerakan barang dan orang harus dapat berjalan secara lancar untuk mempercepat pertumbuhan ekonomi. Sampai saat ini, salah satu jenis infrastruktur yang dapat memberikan dukungan secara langsung adalah infrastruktur jalan. Jalan memiliki peranan penting dalam pengembangan wilayah, dari aspek-aspek ekonomi, sosial, budaya, dan lingkungan. Dengan sifatnya yang fleksibel, karena dapat menjangkau berbagai daerah dan metode pembangunannya yang relatif mudah, jalan menjadi infrastruktur favorit untuk dikembangkan. Untuk menghasilkan kualitas pembangunan jalan yang baik diperlukan suatu spesifikasi umum yang harus dipenuhi. Pada tahun 2014, Direktorat Jenderal Bina Marga mengeluarkan Spesifikasi Umum 2010 Revisi 3 yang dilengkapi dengan dokumen Manual Supervisi Jalan yang mengacu pada spesifikasi tersebut. Namun, dengan meningkatnya kebutuhan akan kualitas pembangunan jalan serta meningkatnya kesadaran akan pentingnya kegiatan pemeliharaan, pada tahun 2018 Direktorat Jenderal Bina Marga mengeluarkan Spesifikasi Umum 2018. Untuk itu, diperlukan pemahaman terhadap perubahan Spesifikasi Umum tersebut dan perubahan Manual Supervisi Jalan.
\end{abstract}

Kata-kata kunci: pembangunan infrastruktur, pembangunan jalan, spesifikasi umum, manual supervisi

\section{PENDAHULUAN}

Jalan sebagai salah satu bagian prasarana transportasi darat memiliki peran yang sangat penting dalam perkembangan suatu wilayah. Undang-Undang Nomor 38 Tahun 2004, 
tentang Jalan, menyatakan bahwa jalan sebagai bagian sistem transportasi nasional mempunyai peranan penting dalam mendukung bidang ekonomi, sosial dan budaya, serta lingkungan, dan dikembangkan melalui pendekatan pengembangan wilayah agar tercapai keseimbangan dan pemerataan pembangunan antardaerah dalam rangka mewujudkan sasaran pembangunan nasional. Peran jalan yang sangat penting ini menyebabkan pemerintah harus bekerja keras dalam mewujudkan infrastruktur jalan yang berkualitas.

Pembangunan jalan memerlukan suatu spesifikasi teknis yang berhubungan dengan pelaksanaan konstruksi jalan tersebut (Johannessen, 2008). Menurut Perpres Nomor 54 Tahun 2010, tentang Pengadaan Barang/Jasa Pemerintah, Kementerian/Lembaga/Satuan Kerja Perangkat Daerah/Institusi lainnya (K/L/D/I) wajib menetapkan spesifikasi teknis sebagai acuan pelaksanaan pekerjaan yang dilelangkan dalam pengadaan barang/jasa. Untuk memenuhi ketentuan tersebut, pada tahun 2014 Kementerian Pekerjaan Umum, melalui Direktorat Jenderal Bina Marga, mengeluarkan Surat Edaran Direktur Jenderal Bina Marga Nomor 10/SE/Db/2014, tentang Penyampaian Standar Dokumen Pengadaan dan Spesifikasi Umum 2010 (Revisi 3), untuk Pekerjaan Konstruksi Jalan dan Jembatan. Selanjutnya, pada tahun 2018, Direktorat Jenderal Bina Marga menerbitkan Spesifikasi Umum 2018 Direktorat Jenderal Bina Marga, melalui Surat Edaran Direktur Jenderal Bina Marga No. 02/SE/Db/2018, untuk menggantikan Spesifikasi Umum 2010 Bina Marga (Revisi 3). Berdasarkan penggantian tersebut, perlu dilakukan pembaruan terhadap manual supervisi jalan terdahulu, yang dibuat berdasarkan Spesifikasi Umum Bina Marga 2010 Revisi 3, untuk menjadi manual supervisi jalan yang sesuai dengan Spesifikasi Umum 2018 Bina Marga.

Dalam kajian ini dibahas mengenai penggunaan manual supervisi dan telaah terhadap perubahan Spesifikasi Umum yang digunakan di Indonesia. Pembahasan pertama adalah tentang penggunaan manual supervisi jalan. Manual supervisi jalan yang ada masih berdasarkan pada Spesifikasi Umum 2010 Bina Marga (Revisi 3), sehingga perlu diganti oleh manual supervisi jalan yang berdasarkan pada Spesifikasi Umum 2018 Bina Marga. Pembahasan selanjutnya adalah telaah terhadap perubahan Spesifikasi Umum 2010 Bina Marga (Revisi 3) menjadi Spesifikasi Umum 2018 Bina Marga.

\section{MANUAL SUPERVISI JALAN}

Menurut Transit New Zealand (2005), dalam pelaksanaan pengawasan kualitas pembangunan dan perbaikan jalan, terdapat beberapa komponen dalam pengawasan yang harus diperhatikan. Komponen-komponen tersebut adalah ketentuan kualitas, metode kerja, daftar inspeksi, dan kontrak kualitas.

Pelaksanaan pengawasan kualitas pembangunan dan perbaikan jalan di Indonesia mengacu pada Spesifikasi Umum yang dikeluarkan oleh Direktorat Jenderal Bina Marga. Dalam membantu pemahaman terhadap spesifikasi umum, perlu disusun suatu manual supervisi. Penyusunan manual supervisi ini dilakukan untuk menjawab permasalahanpermasalahan yang ada di lapangan, terutama permasalahan dalam pemahaman terhadap 
spesifikasi umum tersebut. Manual supervisi yang ada dijabarkan dalam bentuk diagram alir, untuk memberikan pemahaman terhadap urutan proses pelaksanaan pekerjaan sesuai dengan yang dimaksud dalam Spesifikasi Umum.

Selain proses pelaksanaan pekerjaan, manual supervisi ini memberikan peringatan terhadap prasyarat penyelesaian suatu kegiatan, sebelum kegiatan berikutnya dapat dilakukan. Karena itu, manual supervisi disusun dengan skema diagram alir yang dilengkapi dengan tabel kontrol persyaratan. Keunggulan skema seperti ini adalah dimungkinkannya penyajian tahapan pekerjaan, baik yang berurutan maupun yang simultan. Dalam diagram alir tersebut juga terdapat tahapan kontrol yang dihubungkan dengan persyaratan yang ada pada tabel-tabel kontrol. Masing-masing tabel kontrol berisi kriteria yang terdapat pada Spesifikasi Umum Bina Marga. Skema diagram alir dan tabel kontrol disajikan masingmasing pada Gambar 1 dan Tabel 1.

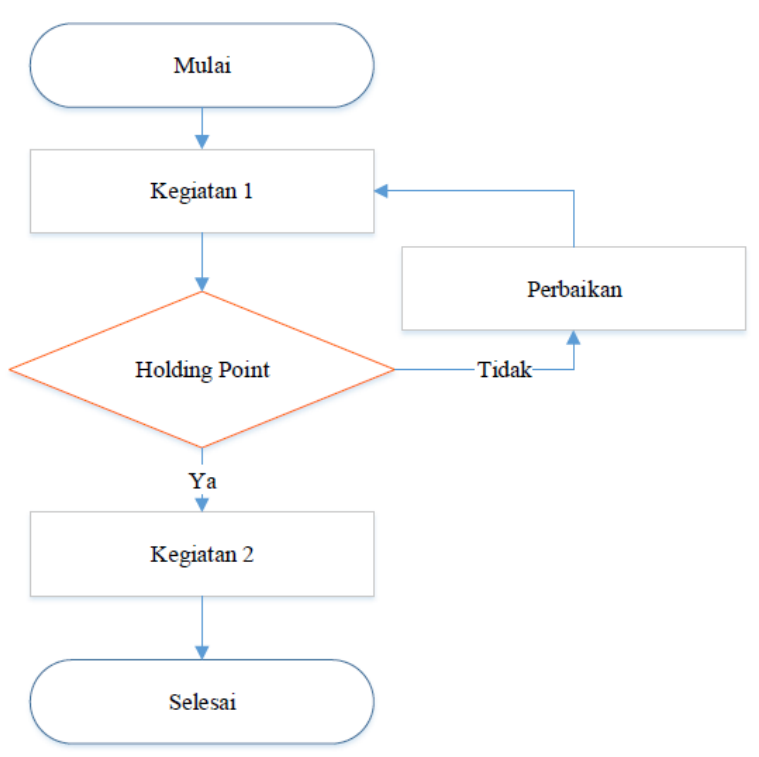

Gambar 1 Skema Diagram Alir Manual Supervisi

Tabel 1 Skema Tabel Kontrol dalam Manual Supervisi

\begin{tabular}{|c|c|c|c|}
\hline $\begin{array}{l}\text { Syarat Pekerjaan } \\
\text { Sebelumnya }\end{array}$ & $\begin{array}{r}\text { Tabe } \\
\text { Pel }\end{array}$ & $\begin{array}{l}\text { ekerjaan yang Menjac } \\
\text { sanaan Kegiatan Selan }\end{array}$ & $\begin{array}{l}\text { Syarat } \\
\text { tnya }\end{array}$ \\
\hline \multirow[t]{2}{*}{ Syarat Penerimaan } & \multirow[t]{2}{*}{ Keterangan } & \multicolumn{2}{|c|}{$\begin{array}{c}\text { Tindak Lanjut } \\
\text { Direksi Pekerjaan }\end{array}$} \\
\hline & & $\mathrm{Ya}$ & Tidak \\
\hline 1. Kriteria Penerimaan & $\begin{array}{c}\text { Referensi dalam } \\
\text { Spesifikasi Umum }\end{array}$ & $\begin{array}{c}\text { Kegiatan selanjutnya } \\
\text { apabila syarat }\end{array}$ & $\begin{array}{c}\text { Suatu kegiatan } \\
\text { penyesuaian apabila }\end{array}$ \\
\hline 2. Kriteria Penerimaan & $\begin{array}{c}\text { Bina Marga } 2010 \\
\text { Revisi } 3\end{array}$ & $\begin{array}{l}\text { penerimaan } \\
\text { dipenuhi }\end{array}$ & $\begin{array}{l}\text { syarat penerimaan } \\
\text { tidak dipenuhi }\end{array}$ \\
\hline
\end{tabular}

Pada Gambar 1 dapat dilihat bahwa setiap proses kegiatan dalam manual supervisi diberi titik kontrol (holding point) supaya dapat disesuaikan dengan tabel kontrol seperti ditunjukkan Tabel 1. Titik dan tabel kontrol tersebut diharapkan dapat memberikan peringatan, bagi pelaksana maupun pengawas konstruksi, untuk memeriksa apakah proses 
yang dilaksanakan sudah sesuai dengan ketentuan. Dengan digunakannya Spesifikasi Umum 2018 Bina Marga, manual supervisi yang dibuat berdasarkan Spesifikasi Umum 2010 Bina Marga (Revisi 3) perlu disesuaikan.

Sebagai contoh penggunaan Manual Supervisi Jalan, berikut dibahas Pekerjaan Pengajuan Kesiapan Kerja Lapis Resap Pengikat dan Lapis Perekat. Sebelum pekerjaan lapis resap pengikat dan lapis perekat dimulai, Direksi Pekerjaan harus menerima, memeriksa, dan menyetujui Kesiapan Kerja Penyedia Jasa, seperti yang ditunjukkan pada Gambar 2.

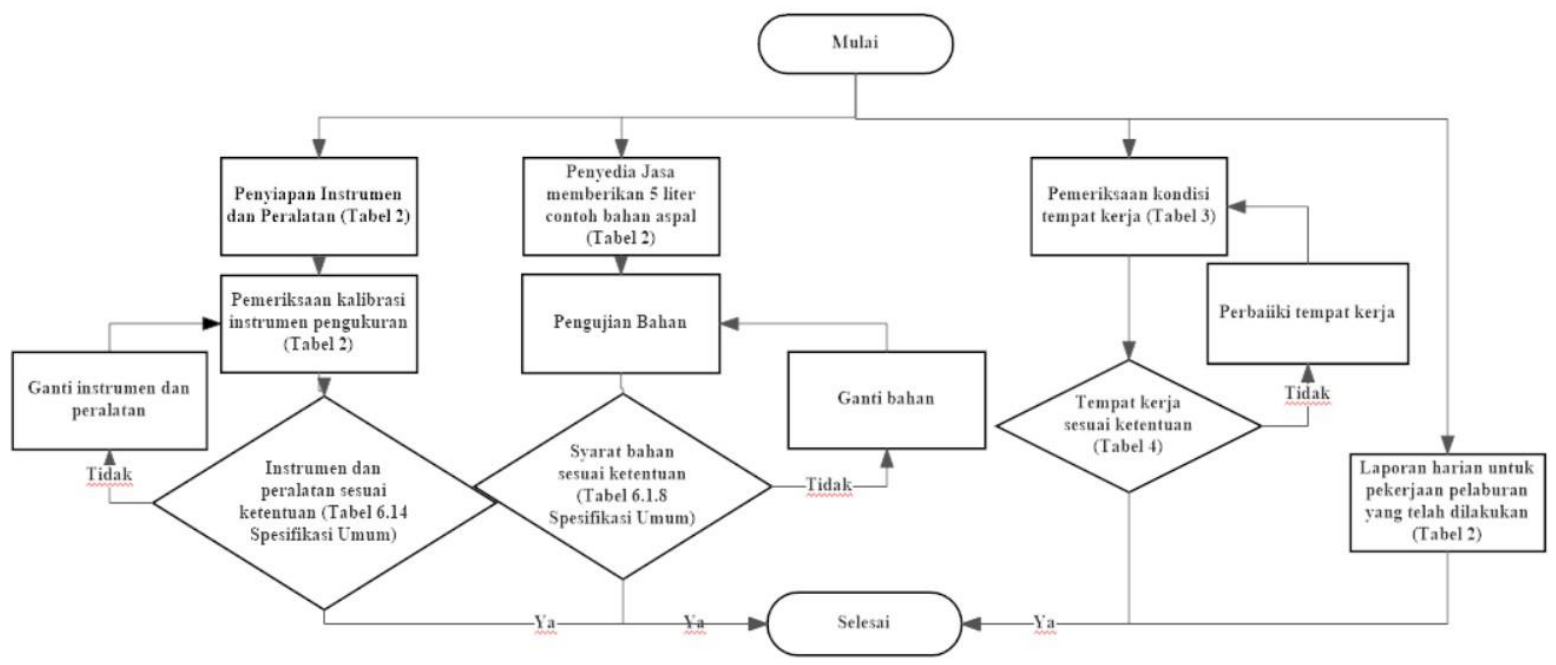

Gambar 2 Diagram Alir Pengajuan Kesiapan Kerja Lapis Resap Pengikat dan Lapis Perekat

Tabel 2 Pengajuan Kesiapan Kerja Lapis Resap Pengikat dan Lapis Perekat

\begin{tabular}{|c|c|c|c|c|c|}
\hline & \multirow{2}{*}{\multicolumn{2}{|c|}{ Syarat Penerimaan }} & \multirow{2}{*}{$\begin{array}{r}\text { Keterangan } \\
\text { Spesifikasi }\end{array}$} & \multicolumn{2}{|c|}{ Tindak Lanjut Direksi Pekerjaan } \\
\hline & & & & $\mathrm{Ya}$ & Tidak \\
\hline 1 & $\begin{array}{l}\text { Lima liter contoh } \\
\text { setiap bahan aspal } \\
\text { diterima dari Penyedia } \\
\text { Jasa dan sudah meme- } \\
\text { nuhi syarat bahan }\end{array}$ & $\begin{array}{c}\text { Tabel 6.1.8; Tabel } \\
\text { 6.1.9; Tabel 6.1.10; } \\
\text { Tabel 6.1.11 } \\
\text { (Dalam Spesifikasi } \\
\text { Umum) }\end{array}$ & $\begin{array}{c}\text { Spesifikasi } \\
\text { Umum } 2010 \\
\text { Rev } 3 \text { Pasal } \\
\text { 6.1.1.(6).(a) }\end{array}$ & $\begin{array}{c}\text { Mengarahkan } \\
\text { Penyedia Jasa } \\
\text { untuk } \\
\text { melaksanakan } \\
\text { penyemprotan }\end{array}$ & $\begin{array}{c}\text { Mengarahkan } \\
\text { Penyedia Jasa } \\
\text { untuk } \\
\text { memenuhi } \\
\text { ketentuan }\end{array}$ \\
\hline 2 & $\begin{array}{l}\text { Pernyataan perihal } \\
\text { instrumen, meteran } \\
\text { pengukur, dan tongkat } \\
\text { celup ukur untuk } \\
\text { distributor aspal }\end{array}$ & $\begin{array}{c}\text { Tabel 6.1.14 } \\
\text { (Dalam Spesifikasi } \\
\text { Umum) }\end{array}$ & $\begin{array}{l}\text { Spesifikasi } \\
\text { Umum } 2010 \\
\text { Rev } 3 \text { Pasal } \\
6.1 .1 .(6) .(b)\end{array}$ & $\begin{array}{l}\text { (Spesifikasi } \\
\text { Umum Tahun } \\
2010 \text { Rev } 3 \\
\text { Pasal 6.1.4) }\end{array}$ & $\begin{array}{l}\text { Pengajuan } \\
\text { kesiapan kerja } \\
\text { (Spesifikasi } \\
\text { Umum Tahun } \\
2010 \text { Rev } 3\end{array}$ \\
\hline 3 & $\begin{array}{l}\text { Ketentuan Grafik } \\
\text { Penyemprotan sesuai } \\
\text { ketentuan }\end{array}$ & $\begin{array}{c}\text { Tabel 6.1.15 } \\
\text { (Dalam Spesifikasi } \\
\text { Umum) }\end{array}$ & $\begin{array}{l}\text { Spesifikasi } \\
\text { Umum } 2010 \\
\text { Rev } 3 \text { Pasal } \\
\text { 6.1.1.(6).(c) }\end{array}$ & & $\begin{array}{l}\text { Pasal } \\
6.1 .1 .(6))\end{array}$ \\
\hline 4 & $\begin{array}{l}\text { Laporan harian untuk p } \\
\text { yang telah dilakukan }\end{array}$ & erjaan pelaburan & $\begin{array}{l}\text { Spesifikasi } \\
\text { Umum } 2010 \\
\text { Rev } 3 \text { Pasal } \\
\text { 6.1.1.(6).(d) }\end{array}$ & & \\
\hline
\end{tabular}

Pekerjaan dapat dilaksanakan jika Pengawas Pekerjaan sudah menyetujui kondisi tempat kerja. Syarat untuk ketentuan kondisi tempat kerja lapis resap pengikat dan lapis perekat ditunjukkan pada Tabel 3. 
Tabel 3 Ketentuan Kondisi Tempat Kerja Lapis Resap Pengikat dan Lapis Perekat

\begin{tabular}{|c|c|c|c|c|}
\hline \multirow{2}{*}{\multicolumn{2}{|c|}{ Syarat Penerimaan }} & \multirow{2}{*}{ Keterangan } & \multicolumn{2}{|c|}{ Tindak Lanjut Direksi Pekerjaan } \\
\hline & & & $\mathrm{Ya}$ & Tidak \\
\hline 1 & $\begin{array}{l}\text { Masih memungkinkan lalu lintas } \\
\text { satu lajur tanpa merusak pekerjaan } \\
\text { yang sedang dilaksanakan }\end{array}$ & $\begin{array}{l}\text { Spesifikasi Umum } \\
\text { 2010 Rev } 3 \text { Pasal } \\
\text { 6.1.1.(7).(a) }\end{array}$ & $\begin{array}{c}\text { Mengarahkan } \\
\text { Penyedia Jasa untuk } \\
\text { melaksanakan }\end{array}$ & $\begin{array}{c}\text { Mengarahkan } \\
\text { Penyedia Jasa } \\
\text { untuk memenuhi }\end{array}$ \\
\hline 2 & $\begin{array}{l}\text { Bangunan-bangunan dan benda- } \\
\text { benda lain di samping tempat kerja } \\
\text { (struktur, pepohonan, dll.) harus } \\
\text { dilindungi agar tidak menjadi kotor } \\
\text { karena percikan aspal }\end{array}$ & $\begin{array}{l}\text { Spesifikasi Umum } \\
\text { 2010 Rev } 3 \text { Pasal } \\
\text { 6.1.1.(7).(b) }\end{array}$ & $\begin{array}{c}\text { penyemprotan } \\
\text { (Spesifikasi Umum } \\
\text { Tahun 2010 Rev } 3 \\
\text { Pasal 6.1.4) }\end{array}$ & $\begin{array}{l}\text { ketentuan kondisi } \\
\text { tempat kerja } \\
\text { (Spesifikasi } \\
\text { Umum Tahun } \\
\text { 2010 Rev } 3 \text { Pasal }\end{array}$ \\
\hline 3 & $\begin{array}{l}\text { Bahan aspal tidak boleh dibuang } \\
\text { sembarangan }\end{array}$ & $\begin{array}{l}\text { Spesifikasi Umum } \\
2010 \text { Rev } 3 \text { Pasal } \\
\text { 6.1.1.(7).(c) }\end{array}$ & & 6.1.1.(7)) \\
\hline 4 & $\begin{array}{l}\text { Terdapat tempat pemanasan dengan } \\
\text { fasilitas pencegahan dan } \\
\text { pengendalian kebakaran yang } \\
\text { memadai }\end{array}$ & $\begin{array}{l}\text { Spesifikasi Umum } \\
2010 \text { Rev } 3 \text { Pasal } \\
\text { 6.1.1.(7).(d) }\end{array}$ & & \\
\hline
\end{tabular}

Direksi Pekerjaan harus memastikan bahwa Pengendalian Lalu Lintas telah dilakukan sesuai dengan ketentuan pada Tabel 4 agar Pekerjaan Lapis Resap Pengikat dan Lapis Perekat dapat dilaksanakan dengan baik. Ilustrasi pengendalian lalu lintas saat pekerjaan dilakukan dapat dilihat pada Gambar 3.

Tabel 4 Ketentuan Pengendalian Lalu Lintas Pekerjaan Lapis Resap Pengikat dan Lapis Perekat

\begin{tabular}{|c|c|c|c|c|c|}
\hline \multicolumn{4}{|c|}{ Pekerjaan Sebelumnya } & \multicolumn{2}{|c|}{ Cek syarat } \\
\hline & \multirow{2}{*}{\multicolumn{3}{|c|}{$\begin{array}{c}\text { Pemeriksaan Kesiapan Kerja } \\
\text { Pemeriksaan Kondisi Tempat Kerja }\end{array}$}} & \multicolumn{2}{|c|}{ Tabel 2} \\
\hline & & & & & bel 3 \\
\hline & \multirow{2}{*}{\multicolumn{2}{|c|}{ Syarat Penerimaan }} & \multirow{2}{*}{ Keterangan } & \multicolumn{2}{|c|}{ Tindak Lanjut Direksi Pekerjaan } \\
\hline & & & & $\mathrm{Ya}$ & Tidak \\
\hline 1 & $\begin{array}{l}\text { Seluruh } \\
\text { petunjuk lalu } \\
\text { lintas } \\
\text { sepanjang } \\
\text { zona kerja } \\
\text { pada setiap } \\
\text { periode } \\
\text { pelaksanaan } \\
\text { sudah tersedia }\end{array}$ & $\begin{array}{l}\text { - Rambu lalu lintas yang } \\
\text { diperlukan } \\
\text { - Barikade } \\
\text { - Rel pengaman lentur atau kaku } \\
\text { - Lampu } \\
\text { - Sinyal } \\
\text { - Marka jalan dan perlengkapan } \\
\text { lalu lintas lainnya } \\
\text { - Manajemen lalu lintas }\end{array}$ & $\begin{array}{c}\text { Spesifikasi } \\
\text { Umum } 2010 \\
\text { Rev } 3 \text { Pasal } \\
\text { 5.1.1.(9) }\end{array}$ & $\begin{array}{c}\text { Proses } \\
\text { Penyiapan } \\
\text { Bahan } \\
\text { (Spesifikasi } \\
\text { Umum 2010 } \\
\text { Rev 3 Pasal } \\
\text { 5.1.2) }\end{array}$ & $\begin{array}{c}\text { Mengarahkan } \\
\text { Penyedia Jasa } \\
\text { agar memenuhi } \\
\text { ketentuan } \\
\text { pengendalian } \\
\text { lalu lintas } \\
\text { (Spesifikasi } \\
\text { Umum 2010 Rev } \\
3 \text { Pasal 5.1.1.(9)) }\end{array}$ \\
\hline
\end{tabular}

\section{SPESIFIKASI UMUM BINA MARGA}

Pemilihan prosedur kerja dan material merupakan salah satu kunci keberhasilan proyek pembangunan jalan di negara tropis dan subtropis (Millard, 2007). Untuk menjamin mutu pelaksanaan pekerjaan pembangunan dan perbaikan jalan di Indonesia, digunakan Spesifikasi Umum Bina Marga.

Pada tahun 2018, Direktorat Jenderal Bina Marga mengeluarkan Spesifikasi Umum 2018 untuk menggantikan Spesifikasi Umum 2010. Spesifikasi Umum 2010 dikeluarkan pertama kali dengan Surat Edaran Direktur Jenderal Bina Marga No. 05/SE/Db/2010 tentang 
Penyampaian Spesifikasi Umum Edisi 2010. Kemudian spesifikasi ini mengalami revisi pertama pada tahun 2011, lalu direvisi kembali tahun 2012, dan revisi ketiga atau terakhir pada tahun 2014, melalui Surat Edaran Direktur Jenderal Bina Marga No. 10/SE/Db/2014. Terdapat beberapa perbedaan antara Spesifikasi Umum 2010 Bina Marga Revisi 3 dan Spesifikasi Umum 2018 Bina Marga. Pada Tabel 5 dapat dilihat rangkuman perbedaan antara Spesifikasi Umum 2013 Bina Marga Revisi 3 dengan Spesifikasi Umum Bina Marga 2018.

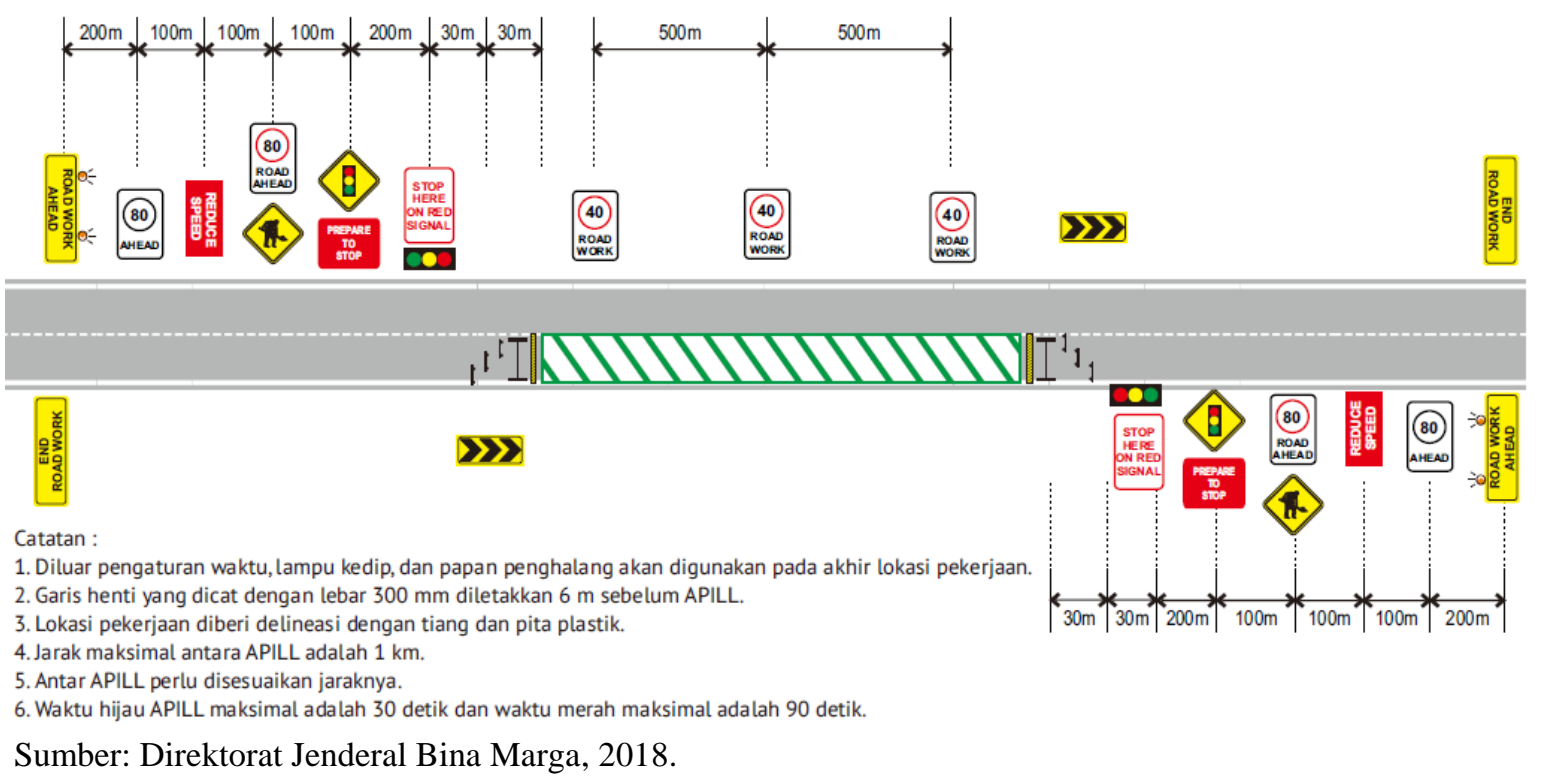

Gambar 3 Ilustrasi Pengendalian Lalu Lintas di Tempat Pelaksanaan Pekerjaan

Perbedaan mendasar dari Spesifikasi Umum 2010 Bina Marga (Revisi 3) dan Spesifikasi Umum 2018 Bina Marga adalah penggantian istilah "Direksi Pekerjaan" menjadi "Pengawas Pekerjaan”. Selain itu, Spesifikasi Umum 2010 Bina Marga (Revisi 3) memiliki 10 Divisi dengan 68 Seksi, sedangkan Spesifikasi Umum 2018 Bina Marga memiliki 10 Divisi dengan 90 Seksi. Perubahan isi divisi yang paling signifikan adalah pada Divisi 4, tentang Pelebaran Perkerasan dan Bahu Jalan, menjadi Divisi Pekerjaan Preventif. Pekerjaan preventif merupakan item pekerjaan baru yang masuk ke Spesifikasi Umum Bina Marga. Pada divisi ini dijelaskan penanganan kerusakan-kerusakan struktural dan fungsional perkerasan, yang pada Spesifikasi Umum 2010 Bina Marga (Revisi 3) tidak dibahas secara khusus.

Perubahan signifikan lain terdapat pada Divisi 8, yang semula menjelaskan tentang Pengembalian Kondisi dan Pekerjaan Minor menjadi Rehabilitasi Jembatan. Rehabilitasi jembatan ini juga tidak dibahas secara khusus pada spesifikasi umum sebelumnya. Pada divisi ini dibahas penanganan kerusakan jembatan dan upaya mempertahankan kondisi jembatan. Perubahan-perubahan yang dilakukan pada Spesifikasi Umum 2018 Bina Marga menitikberatkan pada rincian pekerjaan pemeliharaan untuk mengurangi atau memperlambat kerusakan. 
Tabel 5 Perbedaan Spesifikasi Umum 2010 dan Spesifikasi Umum 2018 Bina Marga

\begin{tabular}{|c|c|c|}
\hline Nama Seksi & Spesifikasi Umum 2010 Rev. 3 & Spesifikasi Umum 2018 \\
\hline DIVISI 1 & UMUM & UMUM \\
\hline SEKSI 1.7 & PEMBAYARAN SEMENTARA & PEMBAYARAN BERSYARAT \\
\hline SEKSI 1.9 & $\begin{array}{l}\text { KAJIAN TEKNIS LAPANGAN } \\
\text { 1) Terdapat Padanan AASHTO, ASTM, } \\
\text { American Standard, British Standard } \\
\text { 2) Penyedia Jasa harus mengikuti ketentuan } \\
\text { yang sudah diberikan oleh Direksi } \\
\text { Pekerjaan }\end{array}$ & $\begin{array}{l}\text { KAJIAN TEKNIS LAPANGAN } \\
\text { 1) Terdapat Padanan Australian } \\
\text { Standard, Germane Institute Standard, } \\
\text { ISO, AASHTO, ASTM, American } \\
\text { Standard, British Standard }\end{array}$ \\
\hline SEKSI 1.14 & PENUTUPAN KONTRAK & $\begin{array}{l}\text { PEMELIHARAAN JALAN YANG } \\
\text { BERDEKATAN DAN BANGUNAN } \\
\text { PELENGKAPNYA }\end{array}$ \\
\hline DIVISI 2 & DRAINASE & DRAINASE \\
\hline DIVISI 3 & PEKERJAAN TANAH & $\begin{array}{l}\text { PEKERJAAN TANAH DAN } \\
\text { GEOSINTETIK }\end{array}$ \\
\hline DIVISI 4 & $\begin{array}{l}\text { PELEBARAN PERKERASAN DAN } \\
\text { BAHU JALAN }\end{array}$ & PEKERJAAN PREVENTIF \\
\hline SEKSI 4.1 & $\begin{array}{l}\text { PELEBARAN PERKERASAN DAN } \\
\text { BAHU JALAN }\end{array}$ & PENGABUTAN ASPAL EMULSI \\
\hline SEKSI 4.2 & BAHU JALAN & LABURAN ASPAL (BURAS) \\
\hline SEKSI 4.3 & Tidak ada & $\begin{array}{l}\text { PEMELIHARAAN DENGAN } \\
\text { LABURAN ASPAL SATU LAPIS }\end{array}$ \\
\hline SEKSI 4.4 & Tidak ada & $\begin{array}{l}\text { LAPIS PENUTUP BUBUR ASPAL } \\
\text { EMULSI }\end{array}$ \\
\hline SEKSI 4.5 & Tidak ada & $\begin{array}{l}\text { LAPIS PERMUKAAN MIKRO ASPAL } \\
\text { EMULSI MODIFIKASI POLIMER }\end{array}$ \\
\hline SEKSI 4.6 & Tidak ada & LAPIS TIPIS ASPAL PASIR \\
\hline SEKSI 4.7 & Tidak ada & $\begin{array}{l}\text { LAPIS TIPIS BETON ASPAL DAN } \\
\text { STONE MATRIX ASPHALT TIPIS }\end{array}$ \\
\hline SEKSI 4.8 & Tidak ada & $\begin{array}{l}\text { PENAMBALAN DANGKAL } \\
\text { PERKERASAN BETON SEMEN } \\
\text { BERSAMBUNG TANPA TULANGAN }\end{array}$ \\
\hline SEKSI 4.9 & Tidak ada & $\begin{array}{l}\text { PENAMBALAN PENUH } \\
\text { PERKERASAN BETON SEMEN } \\
\text { BERSAMBUNG TANPA TULANGAN }\end{array}$ \\
\hline SEKSI 4.10 & Tidak ada & $\begin{array}{l}\text { PENAMBAHAN PENYALURAN } \\
\text { BEBAN PADA PERKERASAN } \\
\text { BETON SEMEN }\end{array}$ \\
\hline SEKSI 4.11 & Tidak ada & $\begin{array}{l}\text { PENJAHITAN MELINTANG PADA } \\
\text { PEMELIHARAAN PERKERASAN } \\
\text { BETON SEMEN }\end{array}$ \\
\hline SEKSI 4.12 & Tidak ada & $\begin{array}{l}\text { PENUTUPAN ULANG SAMBUNAN } \\
\text { DAN PENUTUPAN RETAK PADA } \\
\text { PERKERASAN BETON SEMEN }\end{array}$ \\
\hline SEKSI 4.13 & Tidak ada & $\begin{array}{l}\text { PENSTABILAN DAN PENGEM- } \\
\text { BALIAN ELEVASI PELAT BETON } \\
\text { DENGAN CARA INJEKSI PADA } \\
\text { PERKERASAN BETON SEMEN }\end{array}$ \\
\hline DIVISI 5 & $\begin{array}{l}\text { PERKERASAN BERBUTIR DAN } \\
\text { PERKERASAN BETON SEMEN }\end{array}$ & $\begin{array}{l}\text { PEKERJAAN TANAH DAN } \\
\text { GEOSINTETIK }\end{array}$ \\
\hline SEKSI 5.4 & LAPIS PONDASI SEMEN TANAH & STABILISASI TANAH \\
\hline DIVISI 6 & PEKERJAAN PERKERASAN ASPAL & PEKERJAAN ASPAL \\
\hline SEKSI 6.4 & $\begin{array}{l}\text { LASBUTAG DAN LATASBUTIR (tidak } \\
\text { ada isi dalam Seksi 6.4) }\end{array}$ & $\begin{array}{l}\text { CAMPURAN BERASPAL HANGAT } \\
\text { BERGRADASI MENERUS (LASTON } \\
\text { HANGAT) }\end{array}$ \\
\hline
\end{tabular}


Tabel 5 Tabulasi Perbedaan Spesifikasi Umum 2010 dan Spesifikasi Umum 2018 Bina Marga (Lanjutan)

\begin{tabular}{|c|c|c|}
\hline Nama Seksi & Spesifikasi Umum 2010 Rev. 3 & Spesifikasi Umum 2018 \\
\hline SEKSI 6.5 & $\begin{array}{l}\text { CAMPURAN ASPAL DINGIN } \\
\text { 1) Dalam Spesifikasi Tahun 2010, campuran } \\
\text { aspal dingin dijabarkan dalam } 1 \text { seksi } \\
\text { tersendiri, yaitu Seksi } 6.5 \text { (Spesifikasi } \\
\text { Tahun 2010) }\end{array}$ & $\begin{array}{l}\text { CAMPURAN BERASPAL PANAS } \\
\text { DENGAN ASBUTON } \\
\text { 1) Berbeda dengan Spesifikasi Tahun } \\
\text { 2010, campuran beraspal panas } \\
\text { dengan asbuton dijelaskan secara } \\
\text { singkat dalam seksi } 6.3 \text { (Spesifikasi } \\
\text { Tahun 2010) }\end{array}$ \\
\hline SEKSI 6.6 & $\begin{array}{l}\text { LAPIS PENETRASI MACADAM } \\
\text { 1) Isi Seksi } 6.6 \text { (Spesifikasi Tahun 2010) } \\
\text { merupakan bagian dari Seksi } 6.7 \\
\text { (Spesifikasi Tahun 2018) } \\
\text { 2) Penyedia Jasa harus mengikuti ketentuan } \\
\text { yang sudah diberikan oleh Direksi } \\
\text { Pekerjaan }\end{array}$ & $\begin{array}{l}\text { ASBUTON CAMPURAN PANAS } \\
\text { HAMPAR DINGIN } \\
\text { 1) Dalam Spesifikasi Tahun 2018, } \\
\text { ASBUTON Campuran Panas Hampar } \\
\text { Dingin dijabarkan dalam } 1 \text { seksi } \\
\text { tersendiri, yaitu Seksi } 6.6 \text { (Spesifikasi } \\
\text { Tahun 2018) }\end{array}$ \\
\hline DIVISI 7 & STRUKTUR & STRUKTUR \\
\hline SEKSI 7.5 & $\begin{array}{l}\text { PEMASANGAN JEMBATAN BAJA } \\
\text { STANDAR } \\
\text { 1) Dalam Spesifikasi Tahun 2010, pekerjaan } \\
\text { Pemasangan Jembatan Baja Standar } \\
\text { dijabarkan dalam } 1 \text { seksi tersendiri, yaitu } \\
\text { Seksi 7.5, sedangkan dalam spesifikasi } \\
\text { Tahun } 2018 \text { dibahas dalam Divisi } 8\end{array}$ & $\begin{array}{l}\text { FONDASI TIANG BOR SEKAN } \\
\text { 1) Dalam Spesifikasi Tahun 2018, } \\
\text { pekerjaan Fondasi Tiang Bor Sekan } \\
\text { dijabarkan dalam } 1 \text { seksi tersendiri, } \\
\text { yaitu Seksi 7.5, sedangkan dalam } \\
\text { spesifikasi Tahun } 2010 \text { tidak ada } \\
\text { pembahasan mengenai Fondasi Tiang } \\
\text { Bor Sekan }\end{array}$ \\
\hline SEKSI 7.12 & PERLETAKAN & LANDASAN \\
\hline SEKSI 7.17 & Tidak ada & $\begin{array}{l}\text { PENGUJIAN PEMBEBANAN } \\
\text { JEMBATAN }\end{array}$ \\
\hline DIVISI 8 & $\begin{array}{l}\text { PENGEMBALIAN KONDISI DAN } \\
\text { PEKERJAAN MINOR }\end{array}$ & REHABILITASI JEMBATAN \\
\hline SEKSI 8.1 & $\begin{array}{l}\text { PENGEMBALIAN KONDISI } \\
\text { PERKERASAN LAMA }\end{array}$ & $\begin{array}{l}\text { PERBAIKAN RETAK DENGAN } \\
\text { BAHAN EPOKSI }\end{array}$ \\
\hline SEKSI 8.2 & $\begin{array}{l}\text { PENGEMBALIAN KONDISI BAHU } \\
\text { JALAN LAMA PADA PERKERASAN } \\
\text { BERPENUTUP ASPAL }\end{array}$ & $\begin{array}{l}\text { PERBAIKAN DIMENSI STRUKTUR } \\
\text { BETON }\end{array}$ \\
\hline SEKSI 8.3 & $\begin{array}{l}\text { PENGEMBALIAN KONDISI SELOKAN, } \\
\text { SALURAN AIR, GALIAN TIMBUNAN, } \\
\text { DAN PENGHIJAUAN }\end{array}$ & PENGECATAN STRUKTUR BETON \\
\hline SEKSI 8.4 & $\begin{array}{l}\text { PERLENGKAPAN JALAN DAN } \\
\text { PENGATUR LALU LINTAS }\end{array}$ & PERKUATAN STRUKTUR BETON \\
\hline SEKSI 8.5 & PENGEMBALIAN KONDISI JEMBATAN & $\begin{array}{l}\text { PENGGANTIAN DAN } \\
\text { PENGENCANGAN BAUT }\end{array}$ \\
\hline SEKSI 8.6 & Tidak ada & $\begin{array}{l}\text { PENGELASAN ELEMEN BAJA } \\
\text { STRUKTUR JEMBATAN }\end{array}$ \\
\hline SEKSI 8.7 & Tidak ada & PENGECATAN STRUKTUR BAJA \\
\hline SEKSI 8.8 & Tidak ada & $\begin{array}{l}\text { PERBAIKAN DAN PENGGANTIAN } \\
\text { ELEMEN BAJA }\end{array}$ \\
\hline SEKSI 8.9 & Tidak ada & PERKUATAN STRUKTUR BAJA \\
\hline SEKSI 8.10 & Tidak ada & $\begin{array}{l}\text { PERBAIKAN DAN PENGGANTIAN } \\
\text { STRUKTUR KAYU }\end{array}$ \\
\hline SEKSI 8.11 & Tidak ada & $\begin{array}{l}\text { PERBAIKAN DAN PENGGANTIAN } \\
\text { SAMBUNGAN SIAR MUAI }\end{array}$ \\
\hline SEKSI 8.12 & Tidak ada & $\begin{array}{l}\text { PERBAIKAN DAN PENGGANTIAN } \\
\text { LANDASAN }\end{array}$ \\
\hline SEKSI 8.13 & Tidak ada & $\begin{array}{l}\text { PERBAIKAN DAN PENGGANTIAN } \\
\text { SANDARAN }\end{array}$ \\
\hline
\end{tabular}


Tabel 5 Tabulasi Perbedaan Spesifikasi Umum 2010 dan Spesifikasi Umum 2018 Bina Marga (Lanjutan)

\begin{tabular}{|c|c|c|}
\hline Nama Seksi & Spesifikasi Umum 2010 Rev. 3 & Spesifikasi Umum 2018 \\
\hline SEKSI 8.14 & Tidak ada & $\begin{array}{l}\text { PERBAIKAN DAN PENGGANTIAN } \\
\text { DRAINASE LANTAI JEMBATAN }\end{array}$ \\
\hline DIVISI 9 & PEKERJAAN HARIAN & $\begin{array}{l}\text { PEKERJAAN HARIAN DAN } \\
\text { PEKERJAAN LAIN-LAIN }\end{array}$ \\
\hline SEKSI 9.2 & Tidak ada & PEKERJAAN LAIN-LAIN \\
\hline DIVISI 10 & PEKERJAAN HARIAN & $\begin{array}{l}\text { PEKERJAAN PEMELIHARAAN } \\
\text { KINERJA }\end{array}$ \\
\hline SEKSI 10.1 & $\begin{array}{l}\text { PEMELIHARAAN RUTIN PERKERASAN } \\
\text { BAHU JALAN, DRAINASE, } \\
\text { PERLENGKAPAN JALAN DAN } \\
\text { JEMBATAN }\end{array}$ & PEMELIHARAAN KINERJA JALAN \\
\hline SEKSI 10.2 & $\begin{array}{l}\text { PEMELIHARAAN JALAN SAMPING } \\
\text { DAN JEMBATAN } \\
\text { 1) Seksi 10.2 Spesifikasi Umum } 2010 \\
\text { dijelaskan pada Seksi } 1.14 \text { Spesifikasi } \\
\text { Umum } 2018\end{array}$ & $\begin{array}{l}\text { PEMELIHARAAN KINERJA } \\
\text { JEMBATAN }\end{array}$ \\
\hline
\end{tabular}

\section{KESIMPULAN}

Manual supervisi jalan merupakan perangkat yang sangat dibutuhkan dalam pengawasan pekerjaan konstruksi jalan di lapangan. Manual supervisi yang ada perlu direvisi karena manual yang ada ini didasarkan pada Spesifikasi Umum Bina Marga tahun 2010. Hasil kajian ini diharapkan dapat memberi pemahaman yang komprehensif tentang perubahan spesifikasi umum, dari Spesifikasi Umum 2010 menjadi Spesifikasi Umum 2018, serta perlunya kebutuhan untuk mengubah manual supervisi jalan.

Perubahan isi yang paling signifikan pada Spesifikasi Umum 2010 Bina Marga adalah pada Divisi 4 dan Divisi 8. Perubahan ini tentunya juga akan berdampak pada manual supervisi jalan yang ada.

\section{DAFTAR PUSTAKA}

Direktorat Jenderal Bina Marga. 2014. Surat Edaran Direktur Jenderal Bina Marga Nomor 10/SE/Db/2014 tentang Penyampaian Standar Dokumen Pengadaan dan Spesifikasi Umum 2010 (Revisi 3) untuk Pekerjaan Konstruksi Jalan dan Jembatan. Jakarta: Kementerian Pekerjaan Umum dan Perumahan Rakyat.

Direktorat Jenderal Bina Marga. 2018. Surat Edaran Direktur Jenderal Bina Marga No. 02/SE/Db/2018 tentang Penyampaian Standar Dokumen Pengadaan dan Spesifikasi Umum 2018 untuk Pekerjaan Konstruksi Jalan dan Jembatan. Jakarta: Kementerian Pekerjaan Umum dan Perumahan Rakyat.

Johannessen, B. 2008. Building Rural Roads. Geneva: International Labour Organization. Millard, R.S. 2007. Road Building in the Tropics. New Jersey: John Wiley and Sons, Ltd. Pemerintah Republik Indonesia. 2010. Peraturan Presiden Nomor 54 Tahun 2010 tentang Pengadaan Barang/Jasa Pemerintah. Jakarta. 
Transit New Zealand. 2005. Quality System for Road Construction, Road Maintenance and Structures Physical Contracts having a Normal QA Level. Transit New Zealand, Wellington. 